\title{
CONCEPÇÃO DA VIOLÊNCIA ESCOLAR PARA EDUCADORES DE ESCOLAS MUNICIPAIS DE FEIRA DE SANTANA-BA E FORMAÇÃO DE MULTIPLICADORES PARA CONSTRUÇÃO DA PAZ
}

\author{
Renata Sampaio Santana $^{1}$; Aisiane Cedraz Morais ${ }^{2}$; \\ 1. Bolsista PIBIC/CNPq, Graduanda em Enfermagem, Universidade Estadual de Feira de \\ Santana, e-mail: renatasantanass@ @otmail.com \\ 2. Orientadora, Departamento de saúde, Universidade Estadual de Feira de Santana, e-mail: \\ aisicedraz@hotmail.com
}

PALAVRAS-CHAVE: violência escolar; construção da paz;

\section{INTRODUÇÃOO}

Violência, agressão, bullying, tortura, repressão, chantagem, entre outros, são termos utilizados quando se aborda o tema violência no cotidiano, inclusive na escola (LOPES NETO, 2005). A violência merece atenção especial quando atinge o espaço escolar, já que este é um local de formação social dos alunos, bem como de fortalecimento da identidade e de construção de cidadania (CARDIA, 2006).

Assim, este estudo tem como objetivo analisar os conceitos de violência escolar referidos pelos educadores de escolas municipais de Feira de Santana-BA.

\section{PERCURSO METODOLÓGICO}

Trata-se de uma pesquisa qualitativa, realizada a partir de Banco de dados coletados durante a pesquisa "Diagnóstico da violência e estratégias de construção da paz nas escolas municipais de Feira de Santana-BA", desenvolvida na cidade de Feira de Santana, interior da Bahia, sendo que a coleta foi realizada em Escolas Públicas Municipais.

Trata-se de uma pesquisa-ação, modo de pesquisa que pressupõe interação, imprescindível, entre os envolvidos na situação de pesquisa, pesquisador social e demais implicados, aqui considerados atores sociais. Foi realizado um recorte do banco de dados, utilizando somente como sujeitos os educadores, compondo um total de 17 sujeitos. Esses foram selecionados aleatoriamente dentre as 32 escolas incluídas no Banco de Dados.

Foram utilizadas para este plano de trabalho a entrevista semi-estruturada e utilizamos a Técnica de Análise de conteúdo de Bardin para interpretação dos dados, a qual consiste em identificar a força ou frequência com que aparecem as unidades de significação ou núcleos de sentido, afirmações sobre um determinado assunto em foco, expresso através de uma palavra, frase, resumo, considerando-se as concepções teóricas relacionadas com o objeto de estudo.

Operacionalizada em três etapas:

1. Pré-Análise: leitura flutuante; Constituição do Corpus; Hipóteses emergentes;

2. Exploração do Material: codificação; recorte do texto em unidades de registro; classificação e agregação dos dados em categorias e

3. Tratamento dos resultados obtidos e Interpretação (BARDIN, 1977).

A realização desta investigação foi pautada em todos os preceitos éticos que envolvem Seres Humanos. O projeto foi avaliado pelo CEP/UEFS, que emitiu paracer de aprovação com Protocolo $\mathrm{n}^{\circ} 152 / 2010$, CAE 0150.0.059.000-10. Os educadores foram identificados como P1...P16 e G1, no intuito de manter confidencialidade. 


\section{ANÁLISE DE DADOS}

Numa análise qualitativa, foi possível analisar a concepção da violência escolar segundo os educadores, bem como os fatores contribuintes para a mesma. Foi possível estabelecer as categorias de análise temática, a constar: 1. Compreensões sobre violência para os educadores; 2 . Fatores para ocorrência de violência; e 3. Estratégias de construção da paz.

\section{Compreensões sobre Violência para os Educadores}

Um estudo de Souza (2012) evidencia três formas de expressão da violência escolar, sendo elas: a) violência física, b) violência psicológica e c) violência interpessoal, apontando ainda a agressão física como uma das manifestações mais comuns.

Entretanto, nas falas dos entrevistados foram encontradas as três formas de expressão da violência citadas anteriormente, como nos relatos a seguir:

Abuso da força, ação violenta, constrangimento físico ou moral; Agressão física ou moral entre pessoas, qualquer força empregada contra a vontade, liberdade ou resistência de pessoa ou coisa. (G1)

Tudo que causa mal ao físico e psicológico de alguém; Toda agressão física e emocional. (P14)

Podemos observar nessas, a associação da violência a condições físicas (abuso da força, agressão física), psicológicas (constrangimento moral, sofrimento psicológico, agressão emocional) e à violência interpessoal (contra a pessoa, fazer alguém sofrer), sendo que a interpessoal está imbricada em todo tipo de violência. Encontramos também relatos que enfatizam os sentimentos da vítima, de tristeza e inferioridade:

É machucar não só o corpo, mas a alma, os sentimentos de outra pessoa. (P2)

É um ato de covardia em que o agressor sente o prazer em fazer alguém sofrer; São atitudes que levam um ou mais indivíduos a maltratar o seu próximo, pelo abuso de força ou poder. (P6)

Os educadores relatam ainda a possibilidade da violência escolar gerar um trauma na vítima, o que é corroborado por Netto e colaboradores (2012) ao relatarem que os profissionais de saúde devem possuir escuta e olhar qualificado, pois podem atender crianças e adolescentes que possuam traumas consequentes a violência.

\footnotetext{
É tudo aquilo que pode gerar algum trauma; é a forma que algumas pessoas ou alunos encontram para zoar ou se defender de algo. (P10)
}

A violência, principalmente, a escolar é um desafio para a sociedade. Ela envolve como possíveis prevenções e enfrentamentos: ações de saúde e ações educativas. Deve-se conhecer a realidade vivenciada para que a partir disso possam ser feitas intervenções a fim de minimizar episódios de violência (SANTOS e cols., 2011).

\section{Fatores para Ocorrência de Violência}

Para que sejam adotadas medidas preventivas relacionadas à violência escolar, é necessário que tenhamos entendimento prévio sobres os fatores causais e que colaboram para a ocorrência da mesma e sua reprodução de forma quase cíclica.

Tavares e Pietrobom (2016) relatam que professores e gestores referem à baixa participação dos pais na vida escolar dos filhos como possível causa para a ocorrência da violência no ambiente escolar. Day e colaboradores (2003) afirmam que crianças que 
presenciam a violência conjugal em seus lares, possuem maior risco de desenvolverem condutas agressivas. Pudemos observar esta questão nas falas a seguir:

Porque as crianças presenciam e sofrem violências físicas e/ou psicológicas em casa e acham que também poderá passar o mesmo com outras pessoas. (P6)

Meneghel, Giugliani e Falceto (1998) corroboram com este pensamento quando afirmam que a escola deve se atentar para o adolescente agressor, já que o aluno com atitudes agressivas na escola, é o mesmo que é maltratado em casa. Deve-se pensar em violência doméstica como fator para ocorrência da violência escolar. Em outras falas:

"Não existe educação, respeito ou pais que imponham limites". (P11)

"São inúmeros fatores, entre eles: desestrutura familiar, falta de investimento na educação". (P15)

Podemos observar que os educadores costumam associar o perfil violento do aluno de acordo com a sua estrutura familiar (SALLES; SILVA, 2011). Entretanto, entendemos que a violência se apresenta como um fenômeno pluricausal, como percebemos nos relatos seguintes:

\footnotetext{
"Devido às questões econômicas, politicas e sociais". (P7)

"Fruto da estrutura da sociedade (desestrutura)". (P8)
}

\section{Estratégias de Construção da Paz}

Inicialmente, deve ser pensado em quais as estratégias devem ser adotadas dentro do ambiente escolar. Figueiredo (2013) aponta que não existem políticas nacionais de educação voltadas a esta temática, resultando em educadores que não tenham orientação adequada para se posicionar na ocorrência de episódios violentos.

Nascimento apud Fante (2011) enfatiza que para que se possa desenvolver estratégias de construção da paz nas escolas, primeiro é necessário que os atores inseridos neste espaço tenham consciência da existência da violência escolar e que saibam do que se trata e quais as suas consequências.

A busca por estratégias eficientes tem sido constante, porém, existem atualmente apenas pequenas ações que melhoram o convívio dos alunos e educadores. Ao tempo em que sugere acolhimento, diálogo e escuta sensível dos educadores para com os alunos, bem como a elaboração de projetos pedagógicos que promovam $o$ enfrentamento da violência. Além destes, estabelecer uma boa relação entre a escola e a família, a fim de promover vínculos entre estes (SILVA; COSTA, 2015).

Cientes disso, tentamos participar de uma formação com professores da rede municipal de ensino, na implantação do PREVESC (Projeto Prevenção da Violência Escolar) em conjunto com a Secretaria Municipal de Educação (SEDUC) da cidade de Feira de Santana. Porém, não conseguimos realizar essa ação pela inviabilidade de horário, não sendo possível distribuir o material que havia sido elaborado para exposição na reunião.

\section{CONSIDERAÇÕES FINAIS}

Os educadores entrevistados conceitualizaram a violência escolar de formas semelhantes; porém, ao analisar as falas separadamente, encontramos características específicas em cada uma delas. Constatou-se que a violência física e psicológica foram citadas na mesma proporção, sendo que na maioria dos relatos, aparecem em conjunto. 
Entretanto pôde ser observado que a maioria dos educadores relaciona o aluno violento com fatores externos, seja referindo como fatores causais os problemas familiares, fatores sociais ou outros.

\section{REFERÊNCIAS}

BARDIN, Laurence. Análise de Conteúdo. Lisboa: Edições 70, 1977.

CARDIA, Nancy. Introdução. IN: RUOTTI, C.; ALVES, R.; CUBAS, V. de O.

Violência na escola: um guia para professores. São Paulo: Andhep - Imprensa Oficial do Estado de São Paulo, 2006.

DAY, V. P., et al. Violência doméstica e suas diferentes manifestações. Rev. Psiquiatr. Abril, 2003.

FANTE, Cleo. Fenômeno Bullying: como prevenir a violência nas escolas e educar para a paz. 6. ed. Rev. ampl. Campinas: Verus Editora, 2011.

FIGUEIREDO, Regina et al . Adoção de orientações visando à prevenção da violência contra escolares: uma ação conjunta entre a saúde e a educação. BIS, Bol. Inst. Saúde (Impr.), São Paulo, v. 14, n. 3, ago. 2013.

LOPES NETO, A. A. Bullying: comportamento agressivo entre estudantes. Jornal de Pediatria, 81 (5), 164-172. 2005.

MENEGHEL, S.N.; GIUGLIANI, E. J.; FALCETO, O. Relações entre violência doméstica e agressividade na adolescência. Cad. Saúde Pública, Rio de Janeiro, abrjun 1998.

NETTO, L. et al. Experiências e especificidades da violência escolar na percepção de funcionários de uma escola pública. Rev. Enferm. UFSM. Set/Dez 2012.

SALLES, L. M. F.. SILVA, J. M. A. P. Família e escola: interfaces da violência escolar. São Paulo: Cultura Acadêmica, 2011.

SANTOS, P. A. et al. Estratégias de enfrentamento dos dilemas bioéticos gerados pela violência na escola. Physis - Revista de Saúde Coletiva, 2011.

SILVA, M. K.; COSTA, B. B. A. Violência na escola: sentidos e estratégias docentes no contexto da prática. Revista Ensino Interdisciplinar, v. 1, nº. 02. UERN, Mossoró, RN. Setembro/2015.

SOUZA, K. O. J., Violência em escolas públicas e a promoção da saúde: relatos e diálogos com alunos e professores. Revista Brasileira em Promoção da Saúde, vol. 25, 2012.

TAVARES, P. A.; PIETROBOM, F. C. Fatores associados à violência escolar: evidências para o Estado de São Paulo. Estud. Econ., São Paulo, v. 46, n. 2, p. 471498, Junho 2016. 